\title{
УДК: 338.2
}

\author{
DOI: http://doi.org/10.15350/24097616.2019.4.24
}

\section{МЕСТО КРИПТОВАЛЮТ В МОНЕТАРНОЙ ПОЛИТИКЕ ЕЦБ И БАНКА РОССИИ}

\author{
Невская Наталья Александровна, \\ кандидат экономических наук, доцент, ведущий научный \\ сотрудник отдела экономических исследований, \\ Институт Европы РАН, Москва, Россия. \\ SPIN-код: 3745-2541 / ORCID: 0000-0002-2344-0549 \\ E-mail: nnevskaya@gmail.com
}

\begin{abstract}
Аннотация. Предмет и ичель статьи. Статья раскрывает трансформаџию монетарной политики центральных банков ЕС и России в условиях перехода к ицифровой экономике. Целью статьи является рассмотрение механизмов регулирующего воздействия на криптовалюты на основе нормативно-правовых актов ЕС для оченки условий применения положительного опыта в рыночных условиях иифровой экономики Российской Федерации.

Методы и методология. В работе используются системный подход, методы анализа и синтеза. В частности, в статье изложен анализ динамики рынка криптовалюты (на примере Bitcoin), сравнение показателей роста и прироста основных криптовалют между собой и с основныли товарами фондовой биржи, рассмотрены основные нормативные акты, регулирующие использование криптовалют.

Результатьл. В статье рассмотрена динамика капитализации основных криптовалют, сравнения динамики основных криптовалют между собой, а также с нефтью и золотом. Показано резкое изменение доли сделок, номинированных в фиатных валютах после введения запретов на операчии с криптовалютами. На основе опыта Европейского центрального банка были выявлены основные риски и проблемы регулирования криптовалют, выделены основные направления мониторинга криптовалют. Рассмотрена эволючия нормативного регулирования криптовалют в России, выявлень противоречия правоприменения по отношению $\kappa$ субъектам криптовалютного рынка. На основе анализа динамики капитализачии криптовалюты, с учетом высокого интереса со стороны крупных игроков фондового рынка, с использованием результатов моделирования молодых рынков обосновано формирование предкризисной ситуации в ближайшие 2-3 года.

Область применения. В работе рассматривается система регулирования рынка криптовалют в условиях динамичной циирровизачии мировой экономики. Изложены основные проблемы реализации программы «Цифровая экономика», связанные с технологией блокчейна в России. Особенно важным аспектом является формирование ичифровой архитектуры молодых фондовых рынков.
\end{abstract}

Выводы. Технология распределенных реестров ставит под угрозу монополизм центральных банков. Большая волатильность новых рынков криптовалюты может способствовать нарастанию кризиса и последующей стерилизации денежной массы, выпущенной центральными банками в рамках политики количественного смягчения. $B$ работе выделена законодательных роль развития криптовалют. В рамках глобализачии успешный опыт поддержки может быть применен в реалиях отечественной экономики в формировании архитектуры иฺифровой экономики. 
Ключевые слова: биткоин, ичирровая экономика, фондовая биржа, циифровая экономика, кризис, криптовалюты, цчифровые активы, стоимость криптовалюты, Европейский центральньй банк, банк России.

\title{
CRYPTO-ASSETS STATUS IN THE MONETARY POLICY OF ECB AND BANK OF RUSSIA
}

Natalia A. Nevskaya, Candidate of economics sciences, associate professor, leading researcher of the department of economic research Institute of Europe of RAS, Moscow, Russian Federation. SPIN-code: 3745-2541 / ORCID: 0000-0002-2344-0549 E-mail: nnevskaya@gmail.com

\begin{abstract}
The subject and purpose of the article. The article reveals the transformation of the monetary policy of the central banks of the EU and Russia in the context of the transition to a digital economy. The purpose of the article is to consider the mechanisms of regulatory impact on cryptocurrencies based on EU legal acts to assess the conditions for applying positive experience in the market conditions of the digital economy of the Russian Federation.

Methods and methodology. The work uses a systematic approach, methods of analysis and synthesis. In particular, the article presents an analysis of the dynamics of the cryptocurrency market (for example of Bitcoin), compares the growth and growth rates of the main cryptocurrencies with each other and with the main goods of the stock exchange, considers the main regulatory acts governing the use of cryptocurrencies.

Results. The article discusses the dynamics of capitalization of the main cryptocurrencies, comparing the dynamics of the main cryptocurrencies with each other, as well as with oil and gold. A sharp change in the share of transactions denominated in fiat currencies after the introduction of prohibitions on operations with cryptocurrencies is shown. Based on the experience of the European Central Bank, the main risks and problems of cryptocurrency regulation were identified, the main directions of cryptocurrency monitoring were identified. The evolution of the regulatory regulation of cryptocurrencies in Russia is examined, contradictions of law enforcement in relation to the subjects of the cryptocurrency market are revealed. Based on the analysis of the dynamics of cryptocurrency capitalization, taking into account the high interest from large stock market players, using the results of modeling young markets, the formation of a pre-crisis situation in the next 2-3 years is justified.

Application area. The paper considers the cryptocurrency market regulation system in the context of the dynamic digitalization of the global economy. The main problems of implementing the Digital Economy program related to blockchain technology in Russia are described. A particularly important aspect is the formation of the digital architecture of young stock markets.

Findings. Distributed ledger technology jeopardizes central bank monopolies. The greater volatility of new cryptocurrency markets can contribute to the crisis and the subsequent sterilization of the money supply issued by central banks as part of a quantitative easing policy. In the work, the legislative role of the development of cryptocurrencies is highlighted. Within the framework of globalization, successful support experience can be applied in the realities of the domestic economy in shaping the architecture of the digital economy.
\end{abstract}

Keywords: Bitcoin, digital economy, stock exchange, digital economy, crisis, cryptocurrencies, digital assets, cryptocurrency value, European Central Bank, Bank of Russia.

\section{Введение}


Одним из новых событий на мировом денежном рынке последнего десятилетия является создание криптовалют и распространение технологии блокчейн. В основе криптовалют лежит технология блокчейн, которая может быть использована в различных сферах деятельности и учета. Блокчейн (информационные блоки, соединенные цепочками) это технология ведения распределенных баз данных, имеющая две отличительные особенности: децентрализованная процедура обеспечения интересов всех участников процесса и криптографическая защита данных. Впервые технология была реализована в Биткоине. Стремительный взлет и резкое падение стоимости лидеров среди криптовалют Биткоин (Bitcoin) и Эфириум (Ethereum), привлекли внимание не только специалистов ITотрасли и активных пользователей сети интернет, но затронули и широкие слои населения. Не остались в стороне и Центральные банки стран. Такое внимание связано не только с активной динамикой стоимости, но и с появлением их как конкурента официальным валютам, возможностью обменивать цифровые на наличные деньги. Название «Ethereum» относится как к криптовалюте, так и к платформе, на которой создаются блокчейнприложения, то есть размещаются различные криптовалюты. Наряду с Ethereum существуют платформы Мастерчейн, Hyperlerder fabric, Exonum, C-RDA и другие. Проект Биткоин создавался как платежная система, включающая ограниченный круг лиц для совершения переводов стоимости между ними. Увеличивающиеся технические возможности позволили вовлекать все больше участников в систему, а с достижением определенного порога числа участников появилась возможность увеличивать благосостояние за счет роста цены криптовалюты. Появление криптовалюты способствовало формированию нового фондового рынка криптовалют. Трансформация денежно-кредитного и фондового рынка под воздействием цифровизации экономики предполагает ответные меры со стороны регуляторов. Немногие суверенные регуляторы разработали конкретные решения, нередко применяются судебные прецеденты, особенно на территории английского права. Например, Bitcoin является законным платёжным средством в Японии, в Китае его могут использовать физические лица. В Евросоюзе операции с Биткойнами рассматриваются как платёжные операции с валютами, монетами и банкнотами, и Биткойн не относят к активам, подлежащим налогообложению. Банк Венесуэлы создал Реtro, работают над созданием своей криптовалюты банк Швеции, Эстонии и Китая. Следует отметить, что оборот криптовалют в Китае в настоящее время запрещен. Одной из первых стран, разрешивших выплату заработной платы в Биткоинах, является Новая Зеландия. С 01 сентября 2019 года можно осуществлять выплаты в Биткоинах резидентам, при условии регулярности таких выплат. При этом правила налогообложения остаются неизменными. Изменение отношения к криптовалютам за последнее десятилетие отражает объективную динамику экономического развития, но ряд западных авторов считают, что криптовалюты не могут стать альтернативой реальной валюте. [2]

В статье рассматривается позиция регуляторов двух мировых игроков денежного рынка - Европейского центрального банка и Центрального банка РФ.

Методология исследования. Для рассмотрения проблемы функционирования криптоактивов область исследования ограничена двумя крупнейшими мировыми субъектами международных отношений - Россия и ЕС. Для оценки состояния в сфере регулирования криптовалют проведен контент-анализ нормативно-правовых актов, регулирующих цифровую экономику, анализ динамики рынка криптовалюты и его эволюции в последнее десятилетие. Для более конкретного рассмотрения проблемы объектом исследования среди криптовалют выбран Биткоин.

Авторские концептуальные подходы к решению проблемы и их анализ.

Для формирования основных направлений регулирующего воздействия в монетарной политике необходимо рассмотреть основные риски, которые несет использование криптовалют. Для этого в статье рассматриваются биржевые и фундаментальные риски криптовалют. 


\section{Полученные результаты и их анализ}

Динамика рынка криптовалюты (на примере Bitcoin). Создание Биткоина весной 2009 года способствовало формированию нового фондового рынка криптовалют, который характеризуется волатильностью и неустойчивостью. Становление этого рынка в ретроспективе исторических периодов формирования рынков является быстрым явлением. Всего за 10 лет существования он привлек к себе внимание регуляторов и вызвал бурные дискуссии об экономической сущности и правовом регулировании этой валюты. Но через призму цифровых скоростей можно отметить долгий путь становления этой валюты с последующим раздуванием его стоимости. Биткоин преодолевал государственные запреты и недоверие инвесторов. Тем самым он пробивал дорогу для появления и функционирования других новых видов криптовалюты (которых сейчас насчитывается порядка 300 наименований).

Уровень волатильности данной валюты хорошо видна на рис.1 До 2017 года курс валюты колебался в промежутке 200-1000 долл., со средним показателем цены около 400 долл. В марте 2017 г. он начал резкий рост и к концу года стоил 19345 долл., что в 20 раз превышает показатель начала 2017 года. После пикового значения в декабре он перешёл в падение до 3200 долл. Динамика курса Биткоина в 2019 году демонстрирует повышательную волну, что демонстрирует циклические колебания. Многочисленные прогнозы инвестиционных подразделений банков на основе технического анализа предсказывают положительную динамику и волатильность на данном рынке. На основе серии работ М. Фабера исследуются циклические закономерности функционирования возникающих фондовых рынков.

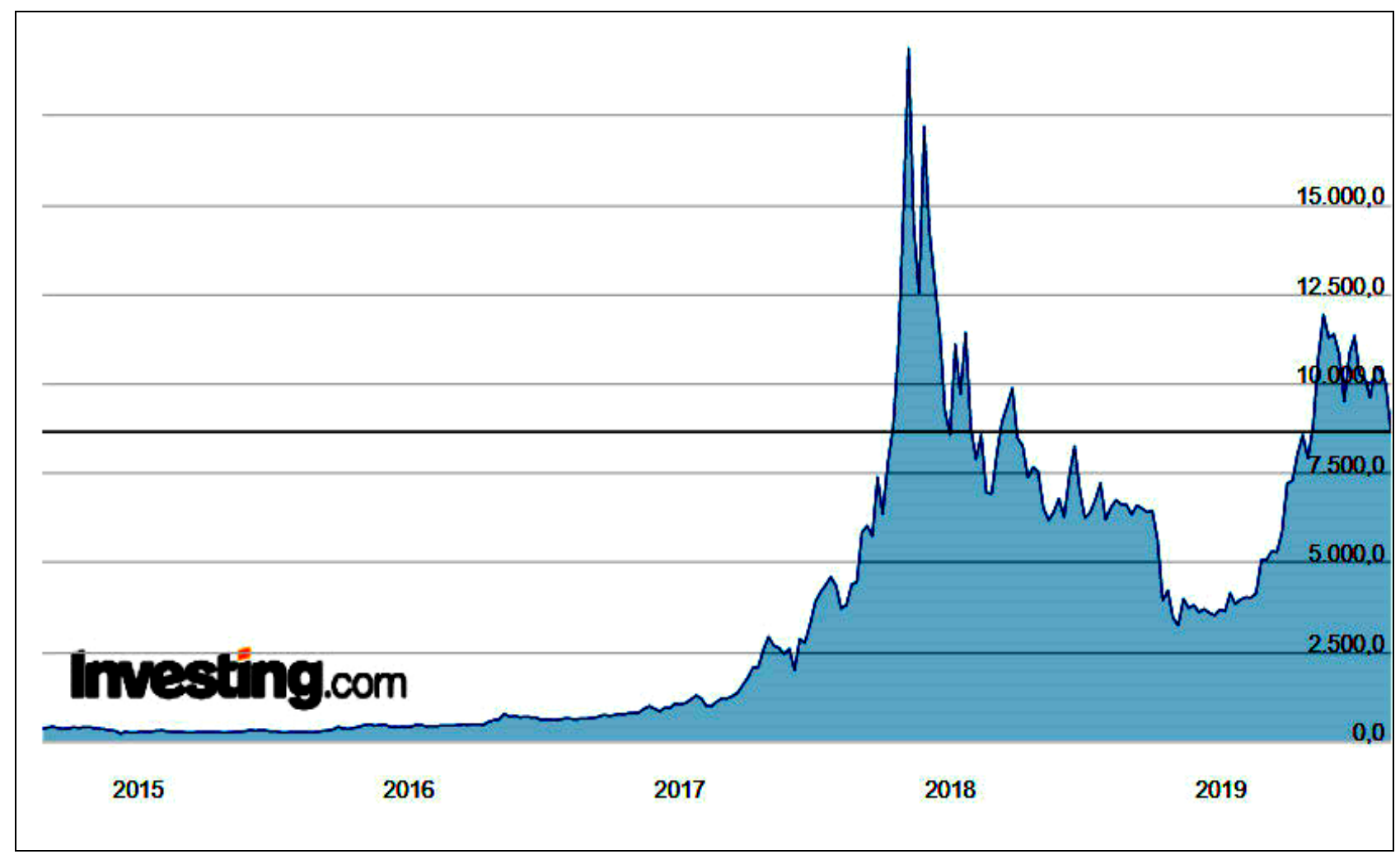

Рис. 1. Динамика курса Биткоин в долларах США за период 2014-2019 гг.

(Источник www.investing.com)

В одном из исследований динамики Биткоина [25] рассчитывается прогноз на основе модели Фабера, результатом которого является завершение в октябре 2019 г. фазы боковика второго цикла динамики курса ВТС и начало фазы роста в третьем цикле в ноябре 2019 г., 
которая может продлиться до конца 2021 года. Прогнозируемый рост курса будет способствовать повышению интереса к данному инструменту фондового рынка.[15] Приход на рынок криптовалют, и Биткоина в частности, крупных игроков способен изменить сложившуюся картину и имеющиеся закономерности, поскольку их финансовые манипуляции будут порождать такие явления как «надувание финансового пузыря», его схлопывание, организованный обвал рынка и т.д. На этот рынок в 2015 году вошли крупные инвестиционные фонды, такие как Rothschild Corporation, UBS, Vanguard, Blackrock и др. Цены на криптоактивы остаются крайне нестабильными (Рис.2).

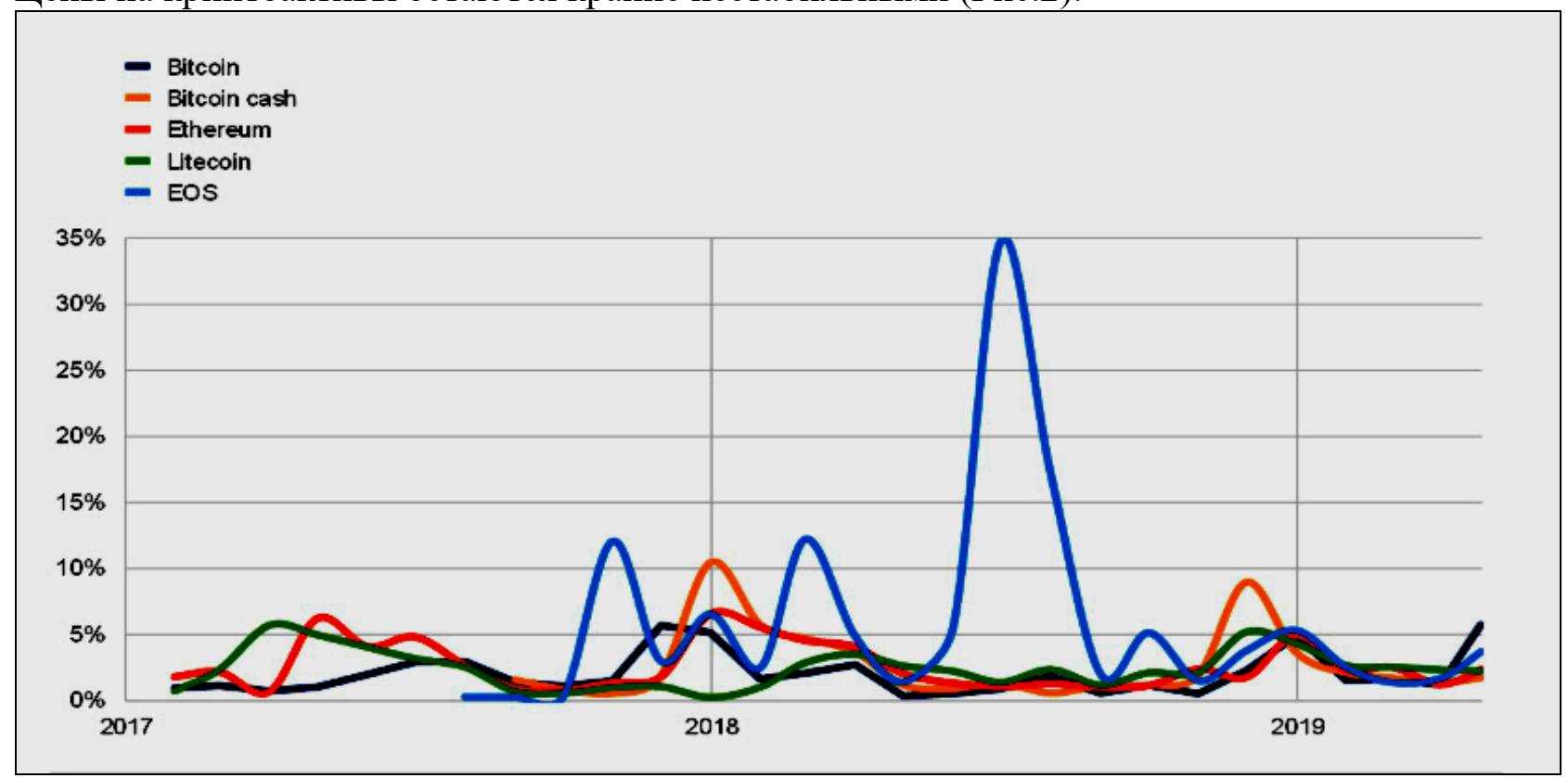

Рис. 2. Динамика криптовалют: Биткоин, Биткоин-кэш, Этериум, Лайткоин,

EOS*.(EOS -внутренняя валюта платформы для разработки децентрализованных приложений.)

За последние два года волатильность криптоактивов превзошла не только волатильность диверсифицированных Европейских рынков акций и облигаций, а также рынки более изменчивой цены нефти и золота. Это подчеркивает рыночный риск, которому подвержены инвесторы в криптоактивы.

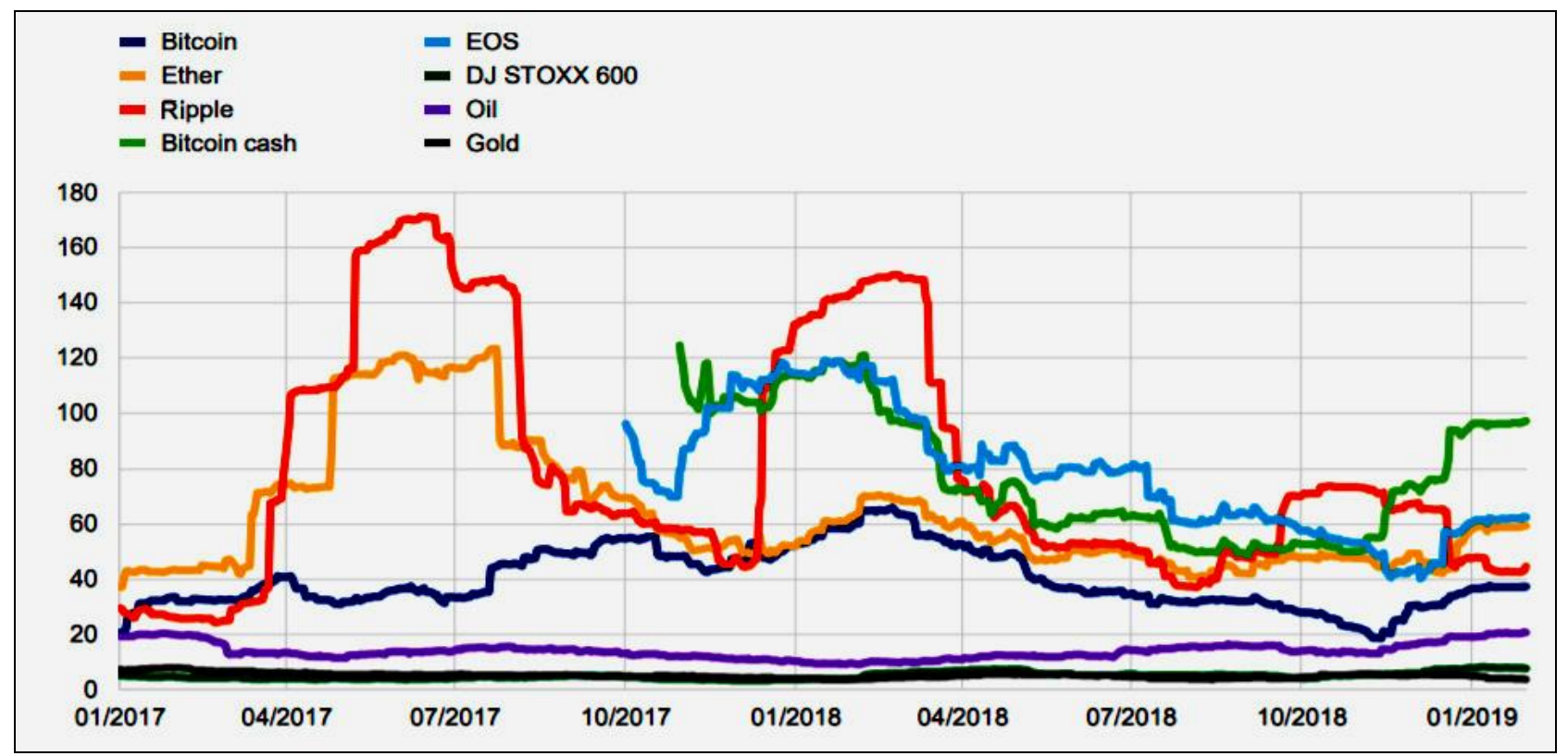

Рис. 3. Динамика курса криптовалют, индекса DJS600, золота и нефти за период 2017-2019 гг. в процентах. 
По сравнению с началом 2018 года, когда курсы нескольких криптоактивов достигли пика, волатильность на фондовом рынке криптовалют стала меньше. Следует отметить, что биткойн не такой волатильный как другие криптоактивы. Как актив потенциально он может привлечь больше инвесторов и на относительно более длительный срок погашения.

\section{Позиция ЕЦБ в отношении криптовалют}

Глава Европейского центрального банка (ЕЦБ) Марио Драги полагает, что криптовалюты не могут заменить реальную валюту и отверг возможность ее выпуска ЕЦБ. Он сообщил, что банк не собирается выпускать свою криптовалюту, но анализирует последствия выдачи такой валюты в качестве дополнения к наличным деньгам. 22 октября 2015 года Европейский суд (European Court of Justice, ECJ) постановил, что операции обмена биткойнов на фиатные валюты освобождаются от НДС. В решении суда уточняется, что закон об НДС распространяется на поставку товаров и оказание услуг[14]. Транзакции в Биткойнах были отнесены к платёжным операциям с валютами, монетами и банкнотами, и потому не подлежат обложению НДС. Суд рекомендовал всем странам-членам Евросоюза исключить криптовалюты из числа активов, подлежащих налогообложению.

Важная доля объема торговли биткойнами рассчитывается в евро, что предполагает заметное воздействие крипто-активов в зоне евро. Торговля в евро колеблется в среднем около $10 \%$ от общего числа сделок с ежедневным стандартным отклонением 2,8\% за последние два года. По сравнению с другими криптовалютами, Биткойн является наиболее востребованным. В течение 2018 года торги объем сделок с Биткойнами составляли в среднем $61 \%$ от общего объема торгов объем торгов фиатными валютами [1].

Все торговые операции в китайских юанях резко упали по сравнению с другими валютами после сентября 2017 года, в связи с изменение китайского законодательство, касающееся операций с Биткойнами (Рис.4).

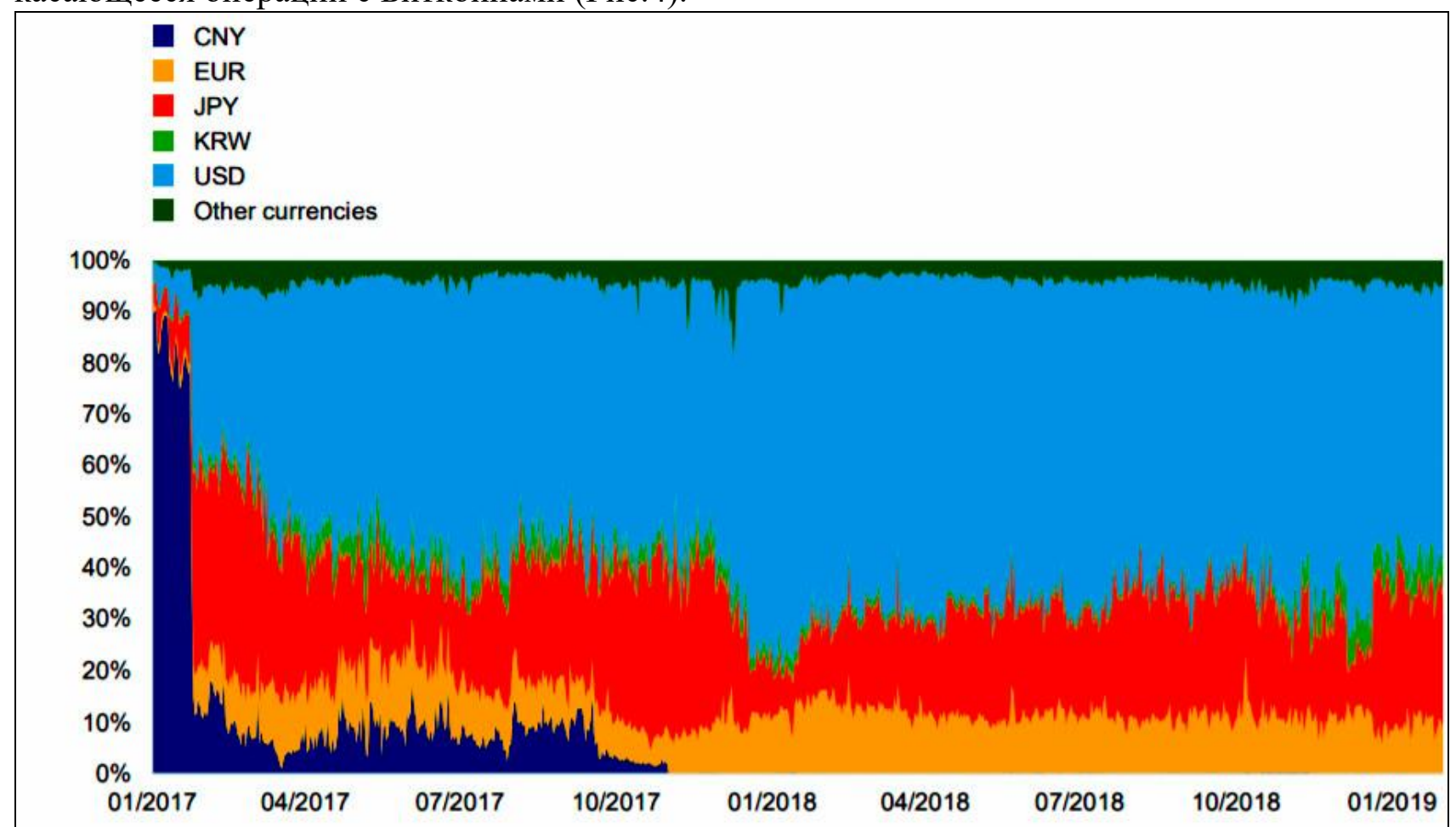

Рис. 4. Распределение доли торгов Биткоином в фиатных валютах: китайский юань, евро, японская йена, корейская вона, доллар США, другие валюты.

В настоящее время ЕЦБ анализирует феномен крипто-активов с целью выявления и мониторинга потенциальных последствий для денежно-кредитной политики и рисков, 
которые крипто-активы могут представлять для бесперебойного функционирования рыночной инфраструктуры и платежей, а также для стабильности финансовой системы [6]. Эта задача реализуется через мониторинг для предоставления аналитических данных, необходимых для постоянной оценки степени и существенности возникающих рисков, связанных с криптоактивами, с целью обеспечения готовности к любым неблагоприятным сценариям.

В своей деятельности по мониторингу ЕЦБ в значительной степени опирается на общедоступные сторонние агрегированные данные [3]. Большая часть агрегированной информации доступна на общедоступных веб-сайтах, которые могут предоставлять, например, метрики для сетей крипто-активов, оценки рыночной капитализации, цены и объемы торговли на крипто-биржах и сумму средств, привлеченных при использовании крипто-актива, а также предлагается общественности в «первичных предложениях монет» (ICO). Эти источники различаются в отношении методологий, которые они используют, полноты охвата данных и доступа к базовой исходной информации, и это лишь некоторые области. Обработка исходной исходной информации (когда она доступна) влечет за собой значительную неопределенность в отношении доступности и качества данных, отчасти из-за отсутствия регулирования у некоторых участников цепочки создания стоимости криптоактивов, чья неконтролируемая деятельность в среде без границ часто препятствует доступу к достоверной информации. Механизмы статистической и надзорной отчетности, как правило, не охватывают криптоактивы (например, подверженность контролируемых учреждений этим активам).

Финансовая система может подвергаться рискам со стороны криптоактивов в зависимости от тесноты их взаимосвязаны. Побочные эффекты могут также передаваться в реальную экономику [5]. В частности, криптоактивы могут иметь последствия для финансовой стабильности и мешать функционированию платежей и рыночной инфраструктуры, a также последствиям для денежно-кредитной политики. Анализ показывает, что, хотя эти риски в настоящее время содержатся и управляются в рамках существующих нормативных и надзорных структур, связи с регулируемым финансовым сектором могут со временем развиваться и расширяться и иметь будущие последствия [4]. Это может повлиять на определение и осуществление денежно-кредитной политики и содействие бесперебойной работе платежных систем, а также на задачи в области банковского надзора и финансовой стабильности. Соответственно, анализ приходит к выводу, что ЕЦБ должен продолжать мониторинг криптоактивов, повышать осведомленность о своих рисках и развивать готовность к любому неблагоприятному сценарию в будущем.

\section{Основные причины возникновения рисков, связанных с крипто-активами:}

1) отсутствие фундаментальной стоимости;

Поскольку у криптоактивов нет основополагающих требований, таких как право на будущий денежный поток или на выполнение любого платежного обязательства, они не имеют фундаментальной стоимости. Это делает их оценку трудной и подверженной спекуляциям. В результате криптоактивы могут испытывать экстремальные колебания цен (риск волатильности), в результате чего их держатели подвергаются потенциально большим убыткам. В зависимости от обстоятельств возможного падения цен последствия могут быть переданы кредиторам держателей (если позиции связаны с левереджем) и другим субъектам.

\section{2) сложностью в регулировании;}

Криптоактивы пока не могут соответствовать характеристикам платежных и финансовых инструментов, так как выходят за рамки действующего регулирования. Учитывая, что они не регулируются, их владельцы не пользуются правовой защитой, связанной с регулируемыми инструментами. Например, в случае банкротства или взлома провайдера криптоактивов, который контролирует доступ к авуарам криптоактивов клиентов (например, провайдерам кошельков-хранителей). На места хранения и серверы также не 
распространяются профилактические меры (например, защита), не используются схемы или другие договоренности для покрытия любых понесенных убытков. Принимая во внимание текущее состояние закона, государственные органы власти имеют ограниченные возможности для регулирования криптоактивов. Любое такое вмешательство может быть дополнительно осложнено отсутствием управления и распределенной архитектурой криптоактивов, а также их трансграничным измерением.

\section{3) отсутствием формальной структуры управления.}

Использование технологии распределенного реестра («distributed ledger technology» DLT) позволяет криптоактивам обходиться без ответственной стороны. Таким образом, обязанности по выявлению, смягчению и управлению рисками, которые несет сеть криптоактивов, не могут быть четко распределены [6]. Из этой характеристики вытекают, среди прочего, повышенные риски отмывания денег и финансирования терроризма в той степени, в которой нет центрального надзорного органа, отвечающего за мониторинг и выявление подозрительных схем транзакций, Правоохранительные органы не могут ориентироваться на местоположение или организацию для проведения следственных действий или конфискация имущества. Ввиду отсутствия формализованного управления, также может быть сложно устранить операционные риски, включая риски кибербезопасности и риск мошенничества [19]. Фактически, в более широкой экосистеме криптоактивов предоставление определенных услуг (например, торговля) часто централизовано. В таких случаях поставщики услуг могут быть определены и привлечены к ответственности. Но это не всегда возможно в децентрализованных моделях, которые минимизируют роль посредников или отменяют ее [18].

Степень, в которой финансовая система и экономика могут подвергаться криптоактивным рискам, зависит от их взаимосвязанности по трем показателям:

1) запасы криптоактивов;

2) инвестиционные инструменты;

3) платежи розничной торговле представляют собой основные связи между рынком криптоактивов, с одной стороны, и финансовыми системами и более широкой экономикой, с другой стороны.

Важную роль в развитии криптобирж и криптовалют играют посредники, которые обеспечивают функции «шлюза», облегчают взаимосвязь между криптоактивами, с одной стороны, и экономическим и финансовым рынками, с другой. Они обеспечивают приток и отток криптоактивов с рынка криптоактивов в финансовые системы и экономику, то есть торговлю криптоактивами и хранение / хранение. Другие функции (например, майнинг) или услуги (например, продвижение ICO) выходят за рамки регулирующего воздействия, поскольку они живут исключительно в экосистеме криптоактивов.

Торговые платформы предоставляют пользователям возможность покупать и продавать криптоактивы [12] в обмен на необязательные валюты или другие криптоактивы. Торговые платформы могут отличаться по своим бизнес-моделям и услугам, которые они предоставляют. Некоторые торговые платформы могут публиковать рыночные котировки, основываясь на торговой активности своих клиентов, и тем самым облегчают ценообразование. Торговые платформы могут также различаться в зависимости от того, владеют ли они криптоактивами от имени своих клиентов и совершают сделки по своим книгам, а не по сети распределенных реестров (DLT). Некоторые централизованные платформы могут предоставлять услуги сверх того, что необходимо для совершения / урегулирования сделки, и в этом случае они также действуют на постоянной основе в качестве поставщиков депозитарных кошельков.

Поставщики кошельков-хранителей позволяют хранить криптографические ключи, которые используются для подписания транзакций с крипто-активами. Инвесторы обычно пользуются услугами провайдера-держателя кошелька из-за удобства и из-за того, что криптографические ключи намного лучше защищены, чем на личном устройстве. 
Размер и степень взаимосвязей, описанных выше, могут иметь значение для стабильности финансовой системы, денежно-кредитной политики и безопасности и эффективности платежей и рыночной инфраструктуры [13].

\section{Позиция Банка России в отношении криптовалют}

На сегодняшний день можно утверждать, что техническое развитие мировой экономики на основе цифровых технологий ушло далеко вперед от правого регулирования отношений субъектов в сфере платежей и расчетов цифровыми активами в Российской Федерации. В январе 2014 г. и в сентябре 2017 г. пресс-служба ЦБРФ выпустила информационное письмо, в котором сообщала, что работа с криптовалютами лежит вне правового регулирования и имеет высокие риски [26]. 28 августа 2017 года Минфин России предложил считать криптовалюту финансовым активом, но регулировать её как «иное имущество».

5 октября 2017 года на сочинском форуме инновационных финансовых технологий Finopolis в Сочи руководитель Банка России Эльвира Набиуллина высказала однозначную позицию: «Мнение Банка России - не легализовывать использование криптовалют как законного платёжного средства. Мы против частных денег, в какой бы форме они ни были материальной или виртуальной. Криптовалюты - это частные цифровые деньги.» Такая активность в обсуждении проблемы использования криптовалют связана не только с изменившимися объективными реалиями, но и с принятием программы «Цифровая экономика», в которой одной из ключевых пунктов программы - развитие сквозных технологий, среди которых упоминается блокчейн [17].

Споры о юридическом статусе криптовалюты не могут перечеркнуть факт ее существования и не умаляют ее влияние на финансовые рынки. Для формирования правил игры на финансовом поле 20 марта 2018 года был внесён законопроект «О цифровых финансовых активах», который прошел с корректировками первое чтение, и в октябре 2019 г. ожидается его рассмотрение во втором чтении [24]. Проектом федерального закона «О цифровых финансовых активах» предлагается урегулировать отношения, возникающие при выпуске, учете и обращении цифровых финансовых активов, а также особенности деятельности оператора информационной системы, в рамках которой осуществляется выпуск цифровых финансовых активов, и оператора обмена цифровых финансовых активов. [14] Закон «о цифровых финансовых активах» должен решить вопрос, будем ли мы запрещать криптовалюты как инструмент обмена в российском законодательстве. То есть не будет пунктов обмена, бирж, которые будут работать с криптовалютами. И мы пока здесь не пришли к согласованной позиции. Необходимо прописать в законодательстве, что такое криптовалюта. Дальше идет развилка: мы запрещаем на территории России организовывать инфраструктуру по приобретению и продаже криптовалют либо разрешаем это», - объяснил глава комитета Госдумы по финрынку, автор законопроекта А.Г. Аксаков [24]. Одна их технологий цифровых денег в России представлена С. Глазьевым [12]. Его позиция не близка ЦБ РФ по ряду причин, в том числе из-за возможности отслеживания использования конкретного рубля в экономике.

В мировой практике выработаны два подхода к регулированию криптовалюты принятие ее как средство платежа или средства обмена, т.е. рассмотрение как объекта вещного права [22]. В Российской Федерации возникла парадоксальная ситуация: нет сформированного подхода к регулированию криптовалют, нет официально принятой терминологии, но есть судебная практика с несколько противоречивыми результатами. С одной стороны, использование криптовалют может рассматриваться как незаконная банковская деятельность, или распространение запрещенной информации, с другой стороны государство признает наличие криптовалют как таковых, и признает доход от них, соответственно, предлагает заплатить налог на доходы с физических лиц от продажи биткоинов [20]. 
Принятие закона «о цифровых финансовых активах» позволит определить позицию государственной власти и Центробанка в отношении криптовалют. В соответствии с ним криптовалюты и токены не получат статус средства платежа, но будут закреплены как имущество. Свидетельством права собственности будет являться регистрация в реестре цифровых трансакций. Новые технологии развиваются уже с учетом открытого алгоритма эмиссионной ренты: это и новые платежные системы, и блокчейновые платформы, и форматы кредитования без обращения к национальным валютам. Эмиссионный формат криптовалюты находит применение в самых разных сферах экономики, переходит с уровня глобальной монополии на эмиссию к региональным эмиссионным центрам и далее - к платформам трансграничных койнов [23].

Столь принципиальная консервативная позиция Центрального банка Российской Федерации по отношению к новым формам денежного обращения может тормозить динамику развития цифровизации национальной экономики, что отразится на основных макроэкономических показателях.

\section{Заключение}

1. Принцип распределённости создания криптоденег ставит под сомнение монополию на производство денег государством. Центральные банки ряда стран, в частности Банк России и ЕЦБ отказались от идеи выпуска собственной криптовалюты. В условиях формирования новой экономики переход от аналоговой формы к цифровизации денег вопрос времени.

2. Развитые страны на уровне исполнительных органов власти государств приняли документы о цифровой трансформации. Это предполагает, что после создания общей платформы и согласования архитектуры, каждый реальный объект будет иметь описание в цифровом виде. С точки зрения монетарной политики властей самой важной характеристикой криптовалют может стать их большая волатильность на фондовом рынке.

3. Биткоин и другие криптовалюты показали в конце 2017 года тренд, называемый «пузырем» - быстрый рост стоимости и ее резкое падение в короткий промежуток времени. Причиной такого движения являлось, в том числе, вхождение на этот рынок крупных инвестиционных фондов (например, Rothschild Corporation, UBS, Vanguard, Blackrock и др.), что в моменте резко изменяло цену Биткоина и сказывалось на среднесрочной динамике.

4. Развитые страны последние годы проводили политику количественного смягчения, наполняли национальные экономики деньгами для стимулирования экономического роста. Криптовалюты могут стать тем пузырем, при помощи которого будет осуществлена стерилизация денежной массы.

5. Трех лет в среднем достаточно для «разгона» рыночной стоимости актива на рынке. По прогнозам многих экономистов к 2021 году мировая экономика войдет в очередную фазу кризиса 10 -летнего цикла. По оценкам ряда специалистов на этот период придется пик курса Биткоина. Есть вероятность, что причиной кризиса станут именно криптовалюты.

6. Регулирование новой динамично развивающейся части финансового рынка имеет некоторую сложность. Предполагается наличие рисков на рынке криптовалют из-за отсутствия ответственности при совершении цифровых сделок, объективной фундаментальной стоимости цифровых активов и технической сложности регулирования.

\section{Литература:}

1. Advice Initial Coin Offerings and Crypto-Assets. 9 January 2019 https://www.esma.europa.eu/sites/default/files/library/esma50-157-1391_crypto_advice.pdf

2. Borio C. On money, debt, trust and central banking // BIS Working Paper, №763. January. 2019 URL: https://www.bis.org/publ/work763.htm.

3. Committee on Payments and Market Infrastructures, Markets Committee.2018, Central bank digital currencies, March. - https://www.bis.org/cpmi/publ/d174.pdf 
4. Crypto-Assets: Implications for financial stability, monetary policy, and payments and market infrastructures // European Central Bank, Financial Stability Review, Frankfurt am Main, May 2019. (дата обращения 19.09.2019)

5. European Central Bank, Financial Stability Review, Frankfurt am Main, May 2018. https://www.ecb.europa.eu/pub/financialstability/fsr/html/ecb.fsr201905 266e856634.en.html\#toc1 (дата обращения 19.09.2019)

6. Financial Stability Board, Crypto-asset markets / Potential channels for future financial stability implications, October 2018 (дата обращения 19.09.2019)

7. Kozyr N.S., Petrovskaya N.E., Zazimko V.L. Modern approaches assessing Global Competitiveness. European Research Studies Journal. - 2018. - Vol. 21. - issue 4. - P. 1034-1041.

8. Rauchs M, Blandin A., Klein K., Pieters G., Recanatini M., Zhang B. 2nd global cryptoasset benchmarking study. Cambridge Centre for Alternative Finance. University of Cambridge Judge $\quad$ Business $\quad$ School. 2018. https://www.jbs.cam.ac.uk/fileadmin/user_upload/research/centres/alternative-finance/ downloads/2019-06-ccaf-2nd-global-cryptoasset-benchmarking.pdf (дата обращения 19.09.2019)

9. Report with advice for the European Commission on crypto-assets. EBA Report. 9 January 2019

URL: https://eba.europa.eu/documents/10180/2545547/EBA+Report+on+crypto+assets.pdf (дата обращения 19.09.2019)

10. Satis Group, "Crypto-asset market coverage initiation: network creation”, July 2018

11. Understanding the crypto-asset phenomenon, its risks and measurement issues // ECB Economic Bulletin, Issue 5. 2019. - https://www.ecb.europa.eu/pub/economicbulletin/articles/2019/html/ecb.ebart201905_03 c83aeaa44c.en.html\#toc1

12. Глазьев С.Ю. О неприемлемости проекта «Основных направлений единой государственной денежно-кредитной политики на 2019 год и период 2020 и 2021 годов» Банка России (особое мнение члена Национального финансового совета) // Российский экономический журнал. - 2018. - № 6. URL: https://elibrary.ru/item.asp?id=36518104

13. Евсеев В.О., Осадчая Г.И., Селезнёв И.А. Применение экспертных систем для оценки интеграционных процессов // Электронный научный журнал «ЦИТИСЭ». [Электронный ресурс]. 2019. № 2 (19). C. 16. URL: https://elibrary.ru/item.asp?id=38505986

14. Законопроект «O цифровых финансовых активах» - URL: https://sozd.duma.gov.ru/bill/419059-7 (дата обращения 19.09.2019)

15. Зарук Н.Ф., Тихонова А.В., Сергеев А.В. Эконометрическое моделирование индикаторов финансовой системы как инструмент макроэкономического планирования // Финансы и кредит. - 2017. - Т. 23. - № 33 (753). - С. 1956-1967. URL: https://elibrary.ru/item.asp?id=30041916

16. Киселев А. Есть ли будущее у цифровых валют центральных банков? // Аналитическая записка Центрального банка РФ. Апрель 2019 - URL: http://www.cbr.ru/Content/Document/File/71328/analytic_note_190418_dip.pdf (дата обращения 19.09.2019)

17. Козырев А.Н. Цифровая трансформация рыночных институтов // Электронный научный журнал «Цифровая экономика» [Электронный ресурс] - 2018. - №4. - C. 5-23 - URL: http://digital-economy.ru/arkhiv-zhurnala/vyshel-chetvertyj-nomer-zhurnala-tsifrovaya-ekonomika (дата обращения 19.09.2019)

18. Козырь Н.С., Толстов Н.С. Взаимосвязь денежно-кредитной политики РФ и темпов экономического роста // Экономика и предпринимательство. - 2015. - № 12-1 (65). - С. 84-90. URL:https://elibrary.ru/item.asp?id=25031403

19. Невская Н.А. Цифровая безопасность экономики Великобритании: опыт регулирования и эффективность применения // Электронный научный журнал «ЦИТИСЭ». [Электронный ресурс]. - 2019. - № 1 (18). - C. 28. URL: https://elibrary.ru/item.asp?id=37292601

20. Об использовании частных «виртуальных валют» (криптовалют). Центральный банк Российской Федерации (Банк России). Пресс-служба - URL: 

обращения 19.09.2019)

21. Обмен традиционных валют на виртуальную валюту «Биткойн» освобождается от НДС. Пресс-релиз Европейского суда № 128/15 от 22 октября 2015

22. Овчинников А. И., Фатхи В. И. Правовое регулирование криптовалют в России: современное состояние и перспективы развития // Юристь - Правоведъ. - 2018. №4. - C.17-24. URL: https://elibrary.ru/item.asp?id=36914794

23. Остарков Н.А. Эмиссионная формация. Локальные деньги вместо глобальной монополии на эмиссию // Электронный научный журнал «Цифровая экономика». [Электронный ресурс]. - 2019.URL: http://digital-economy.ru/mneniya/emissionnaya-formatsiyaot-globalnoj-monopolii-na-emissiyu-k-lokalnym-dengam (дата обращения 20.09.2019)

24. Регулирование криптовалют в России перенесут на осень // РБК. 09.07.2019. URL: https://www.rbc.ru/crypto/news/5d24a89a9a794712ab561e92 (дата обращения 19.09.2019)

25. Торжевский К.А. Применение модифицированной модели М. Фабера для прогнозирования рынка криптовалюты // Электронный научный журнал «Цифровая экономика». - 2019. URL: http://digital-economy.ru/images/easyblog_articles/550/fab324.pdf (дата обращения 24.09.2019)

26. Третьякова С.Н. Денежно-кредитное регулирование в условиях финансовой нестабильности // Экономика: теория и практика. - 2016. - № 1 (41). - C. 57-63. URL https://elibrary.ru/item.asp?id=25741057

\section{References:}

1. Advice Initial Coin Offerings and Crypto-Assets. 9 January 2019. URL: https://www.esma.europa.eu/sites/default/files/library/esma50-157-1391_crypto_advice.pdf

2. Borio C. On money, debt, trust and central banking. BIS Working Paper, №763, January 2019. URL: https://www.bis.org/publ/work763.htm.

3. Committee on Payments and Market Infrastructures, Markets Committee, Central bank digital currencies, March 2018. URL: https://www.bis.org/cpmi/publ/d174.pdf

4. Crypto-Assets: Implications for financial stability, monetary policy, and payments and market infrastructures. European Central Bank, Financial Stability Review, Frankfurt am Main, May 2018.

5. European Central Bank, Financial Stability Review, Frankfurt am Main, May 2018. URL: https://www.ecb.europa.eu/pub/financialstability/fsr/html/ecb.fsr201905 266e856634.en.html\#toc1

6. Financial Stability Board, Crypto-asset markets / Potential channels for future financial stability implications, October 2018.

7. Kozyr N.S., Petrovskaya N.E., Zazimko V.L. Modern approaches assessing Global Competitiveness. European Research Studies Journal, 2018, no. 21. issue 4, pp. 1034-1041. (in Russian)

8. Rauchs M, Blandin A., Klein K., Pieters G., Recanatini M., Zhang B. 2nd global cryptoasset benchmarking study. Cambridge Centre for Alternative Finance. University of $\begin{array}{lllll}\text { Cambridge } & \text { Judge } & \text { Business } & \text { School. } & \text { Dec. }\end{array}$ https://www.jbs.cam.ac.uk/fileadmin/user_upload/research/centres/alternative-finance/ downloads/2019-06-ccaf-2nd-global-cryptoasset-benchmarking.pdf (дата обращения 19.09.2019)

9. Report with advice for the European Commission on crypto-assets. EBA Report. 9 January 2019

URL: https://eba.europa.eu/documents/10180/2545547/EBA+Report+on+crypto+assets.pdf

10. Satis Group, "Crypto-asset market coverage initiation: network creation", July 2018.

11. Understanding the crypto-asset phenomenon, its risks and measurement issues // ECB Economic Bulletin, Issue 5. 2019. - https://www.ecb.europa.eu/pub/economicbulletin/articles/2019/html/ecb.ebart201905_03 c83aeaa44c.en.html\#toc1 
12. Glazyev S.Yu. On the unacceptability of the project "The main directions of the unified state monetary policy for 2019 and the period 2020 and 2021" of the Bank of Russia (special opinion of a member of the National Financial Council). Russian Economic Journal, 2018, no.6. (in Russian) URL: https://elibrary.ru/item.asp?id=36518104

13. Evseev V.O., Osadchaya G.I., Seleznev I.A. The use of expert systems for assessing integration processes. CITISE, 2019 no. 2 (19), pp. 16. (in Russian) URL: https://elibrary.ru/item.asp?id=38505986

14. The bill "On digital financial assets" - URL: https://sozd.duma.gov.ru/bill/419059-7 (Released September 19, 2019) (in Russian)

15. Zaruk N.F., Tikhonova A.V., Sergeev A.V. Econometric modeling of indicators of the financial system as an instrument of macroeconomic planning. Finance and Credit, 2017, no. 23. no. 33 (753, pp. 1956-1967. (in Russian) URL: https://elibrary.ru/item.asp?id=30041916

16. Kiselev A. Is there a future for digital currencies of central banks? Analytical note of the Central Bank of the Russian Federation. April 2019. URL: http://www.cbr.ru/Content/Document/File/71328/analytic_note_190418_dip.pdf (Released September 19, 2019) (in Russian)

17. Kozyrev A.N. Digital Transformation of Market Institutions. Electronic Scientific Journal Digital Economy, 2018. no. 4 pp. 5-23. (in Russian)

18. Kozyr N.S., Tolstov N.S. The relationship of monetary policy of the Russian Federation and the rate of economic growth. Economics and Entrepreneurship, 2015, no. 12-1 (65), pp. 84-90. (in Russian) URL:https://elibrary.ru/item.asp?id=25031403

19. Nevskaya N.A. Digital security of the UK economy: regulatory experience and application efficiency. CITISE, 2019, no 1 (18), pp $28 . \quad$ URL: https://elibrary.ru/item.asp?id=37292601 (in Russian)

20. On the use of private "virtual currencies" (cryptocurrencies). Central Bank of the Russian Federation (Bank of Russia). Press Service - URL: https://www.cbr.ru/press/pr/?file=04092017_183512if2017-09-04T18_31_05.htm （Released September 19, 2019) (in Russian)

21. The exchange of traditional currencies for virtual currency "Bitcoin" is exempt from VAT. European Court Press Release no. 128/15 of October 22, 2015 (in Russian)

22. Ovchinnikov A. I., Fathi V. I. Legal regulation of cryptocurrencies in Russia: current status and development prospects. Lawyer - Jurisprudence, 2018, no 4, pp.17-24 (in Russian) URL: https://elibrary.ru/item.asp?id=36914794

23. Ostarkov N.A. Emission formation. Local money instead of a global monopoly on emissions. Digital Economy, 2019. (in Russian)

24. Regulation of cryptocurrencies in Russia will be transferred to the fall. RBC. 07/09/2019. - URL: https://www.rbc.ru/crypto/news/5d24a89a9a794712ab561e92 (Released 09/19/2019) (in Russian)

25. Torzhevsky K.A. The use of a modified model of M. Faber for forecasting the cryptocurrency market. Digital economy, 2019. (in Russian)

26. Tretyakova S.N. Monetary regulation in the conditions of financial instability. Economics: theory and practice, 2016, no. 1 (41), pp. 57-63. (in Russian) URL https://elibrary.ru/item.asp?id=25741057

Submitted: 01 September 2019 Accepted: 27 September 2019 Published: 29 September 2019 